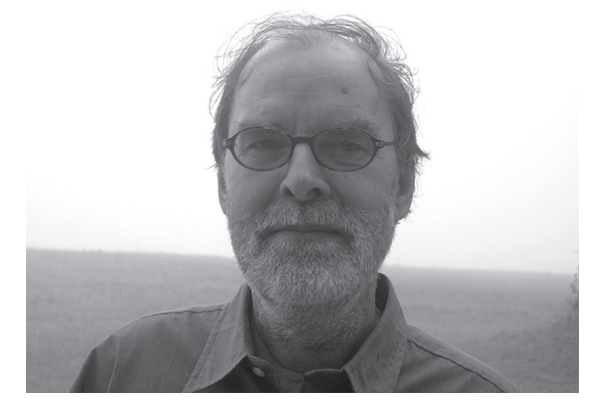

\title{
The origins of research on defensive expenditures: a dialog with Christian Leipert
}

\author{
C. Leipert $^{1}$ and F.M. Pulselli ${ }^{2}$ \\ ${ }^{1}$ Institute of Economic-Ecological Research, Berlin, Germany. \\ ${ }^{2}$ Department of Chemical and Biosystems Sciences, University of Siena, Siena, Italy.
}

\section{INTRODUCTION}

Human pressure on the planet earth is increasing. Uncontrollable and unpredictable factors, such as population growth, catastrophes, migration dynamics and climate, can quite quickly change social, economic, and environmental conditions anywhere in the world. Since everything is linked to the complex network of relations constituting ecosystems, any human action can have consequences that may manifest in different time and spatial scales. Most human activities are driven by economic aims, and most economic benefits are expected in the short term and in a particular place. Attention is seldom paid to the long-term or global consequences of human behavior. The effects most often ignored are social and environmental ones, to the detriment of the welfare of weaker populations and the environment. Though world summits, scientific conferences and governmental and intergovernmental meetings discuss climate change, food, poverty, inequality and sustainable development, political solutions are seldom found. Why is it so difficult to reach a compromise, or why do compromises only lead to weak provisions and solutions? Is it because the foundations of international politics are not solid enough to build anything other than non-binding general agreements? Or is the political-institutional element only a façade of the economic edifice that guides the behavior of states and populations? The economic system pursues objectives that are limited in time and space and uses instruments that are incompatible with the complexity of the ecosystems on which it rests, apparently oblivious to long-term prospects and its own capacity to survive indefinitely. It would be important to reconsider economic instruments for evaluating human behavior, such as the measure of national income, GDP.

In the 1970s, various events concerning the relationship between human activity and the natural environment made an impression on economists and non-economists. Much essential literature was published and the concept of defensive expenditures was introduced by Christian Leipert, a German 
economist studying the system of national accounting. After establishing contact with Simon Kuznets, he began work at the frontier between economics and ecology. What does 'defensive' really mean? Who are we defending from what? These questions are answered here and an attempt is made to clarify the role that modern economics should play in society. In discussing evolution of the concept of defensive expenditures since the early 1970s, economic and social issues are also tackled: the importance of environmental consciousness, the contribution of ecological economics, expectations and hopes for these ideas that are still considered unorthodox, and steps towards transdisciplinary science.

\section{INTERVIEW}

Federico Maria Pulselli (FMP): What were the main problems that stimulated research into the system of national accounts in the 1970s?

Christian Leipert (CL): A new problem emerged at the end of the 1960s and the beginning of the 1970s. It was the experience of environmental disruption - air and water pollution, which inter alia impaired the health of the population; noise pollution, induced by the rising car traffic, which deteriorated the quality of life. These new problems were perceived as by-products of the economic growth and spatial concentration process. The awareness of negative side effects of economic growth appeared first in the agglomerated urban areas, where these signs of decreasing quality of life mainly came forward.

Economic growth was a main objective in the industrial world. It was equated with an increase in economic welfare, with a rise in the living standard of the population. But this equation was now criticized in the light of the new environmental problems which were experienced as a direct consequence of rapid economic growth. In these years, the environmental movement came into existence. And environmentalists were among the first to criticize the negative environmental effects of economic growth and also question the concrete measure of economic growth, namely the GDP and the system of national accounts by which it is calculated.

A policy of purely quantitative growth was criticized. An economic production model which resulted in an environmentally destructive economic growth could no longer be legitimized. The aim was a new policy of qualitative growth, of differentiated growth, with a growth pattern which is environmentally friendly and increases the quality of life.

The new concept 'quality of life' emerged in the early 1970s. The first influential politicians - like German left-wing socialdemocrat E. Eppler - argued for a new policy of qualitative growth, which would be measured by improvement in quality of life. In these years, there emerged literally a "quality of life' movement, which was inspired by a growing research community of mainly sociologists, who worked on the development of social indicators ('social indicator movement'). They started in the mid-1960s, largely in reaction to the idea that ' $\ldots$ national economic accounting was promoting a new philistinism - an approach to life based on the principle of using monetary units as the common denominator of all that is important in life' ([1], p. 167). They argued that concepts like social welfare or quality of life should not be calculated by a one-dimensional measure like GDP, but by a bundle of separate indicators.

FMP: Who were the main figures to inspire you in that period?

CL: The person who most influenced my PhD work 'Inadequacies of the national product as a measure of welfare' [2] was Simon Kuznets, winner of the Nobel Prize for Economics in 1971. He was the forerunner of this whole line of research and very influential in the first wave of research between 1965 and 1973. Interestingly enough, he won the Nobel Prize not for his critical work on national 
accounts, but for his longitudinal and cross-sectional studies on economic growth and income distribution in industrial and developing countries.

The research on the inadequacies of GDP (a measure of growth) as a welfare indicator is very close to a criticism of the growth paradigm. In economic science and the political sphere, there is strong resistance against questioning the growth pattern of our market economy and against replacing this purely market-orientated, undifferentiated measure of economic growth with a differentiated, welfare-orientated measure of net product.

When asked ([3], p. 361) why he remained almost the sole prominent economist to insist on a substantial (and not only formal) final product orientation of the concept of GDP in the decisive debate in the 1940s about the main objective of the newly developed system of national accounts (1940s), Kuznets replied that his entire career as an economist had been based on the premise that economic activities must serve the needs of mankind. This meant that GDP should be a criterion for measuring the net production of a society, which has a positive value in relation to human needs. ('We assume that the goal of economic activity is to satisfy wants of individual consumers who are members of the nation, present and future. This is the only goal that seems to underlie the performance of a variety of economies and the only one that can be associated with the economic aspect of social welfare' ([4], p. 180).) Welfare comparisons are a long-term issue: 'It is clearly the ... use of a period long enough for ... structural changes, changes in conditions of life, and the sources of the large advances in both positive output and negative by-products to be observed' ([5], p. 586).

The main contributions of Kuznets to the debate on the deficiencies of the GDP as a final, productorientated measure of economic welfare appeared between 1946 and 1954. They were rediscovered at the end of the 1960s. Although Kuznets was one of the first to formulate and explore in detail those elements of criticism of GDP that are still considered essential, he never produced an empirical calculation of a welfare-orientated measure of net production that satisfied his main objections. He never went further than calculating partial aspects (such as additional agglomeration and industrialization costs to deduct), and even this was usually in the context of welfare comparisons between industrial and developing countries [6]. In 1968, Sametz published the first example of a modified measure of net national welfare [7]. Afterwards, Nordhaus and Tobin [8], the Economic Council of Japan [9] and the Greek central banker Zolotas [10] proposed further examples of welfare-orientated revisions of GDP.

Sametz was the first to tackle the task of developing a net national welfare measure for the United States from existing GDP calculations. His work could have been done by Kuznets himself; all the basic calculations, subtractions and additions to GDP in his approach belong to the Kuznets critical tradition. Sametz and Nordhaus and Tobin did not consider environmental deterioration and resource depletion in their approaches. In 1968 this was not surprising. Nor did Kuznets mention environmental issues, understandable in the period when he wrote his major articles in this field.

The most influential idea of Kuznets - seen from today - is that certain (seemingly) final outlays of private households, enterprises and the public sector are substantially costs induced by negative effects of economic growth that impair people's environmental, living, and working conditions. These costs were originally called costs of maintaining the social framework, industrialization and urbanization costs, regrettable necessities, and in the course of the 1970s, compensatory or defensive expenditures (see next question).

Kuznets was very clear about the old question 'what is final and what is intermediate activity?': 'National income is a measure of net output of economic activity in the given social framework, not of what it would be in the hypothetical absence of the latter. The maintenance and modification of this framework, even though it employs scarce resources that may be secured on business markets, cannot in itself constitute part of the final product of economic activity' ([4], p. 193). 'Most governmental 
activities are designed to preserve and maintain the basic social framework and are thus a species of repair and maintenance which cannot in itself produce net economic returns' ([4], p. 184). In his 'Concluding Remarks' of a conference reader on the subject in 1973, he calls the intermediate expenditures of repair and maintenance 'regrettable necessities', 'that are either offsets to productioninduced costs, or intermediate products, being costs of running the machinery of society and the state' ([5], p. $580 \mathrm{f}$.).

The identification of types of expenditures '... that are results of changed conditions of production and are required for the changed role of the consumer as producer ...' ([5], p. 580) is also required in the case of personal consumption expenditures. 'Unquestionably, in our industrial urban civilization, many items of ultimate consumption are chosen for the sake of productive efficiency, and could be classified as intermediate rather than ultimate consumption' ([11], p. 116).

The debate on concrete approaches for an empirical calculation of a measure of net product or net consumption was always accompanied by blaming these for producing arbitrary results. There are, in fact, serious problems in identifying, measuring, and monetizing various social costs of economic growth. The identification of causal relationships, for instance, between environmental pollution and damage to health, materials, buildings, and vegetation encounters difficulties, since negative effects are often caused by a multiplicity of factors.

Personally, I agree with Daly, when he stresses the need, in the present situation, to develop new concepts even if it is not yet possible to apply them empirically in a satisfactory manner in every point. 'But is not even the poorest approximation to the correct concept always better than an accurate approximation to an irrelevant or erroneous concept? It is admittedly an exaggeration to say that GNP is worse than nothing, but I suspect that the world could get along well enough without it, as it did before 1940. We must face the question of what you would put in its place, but without letting its operational difficulty be converted into an argument for staying with the (misleading) GNP' ([12], p. 18 f.). The currently prevailing production, income, and growth concepts and calculations are only seemingly objective, valid, and 'modern'. They benefit from the fact that the goods and services produced are valued at market prices which seem to be self-evident. Crucially, though, the market prices of today are determined with essentially no allowance for the external environmental costs of production and consumption or for the resource depletion costs, and are therefore far removed from the ecological 'truth'.

The next phase of research, beginning in the second half of the 1970s, focused mainly on the deficiencies of GDP regarding the treatment of environmental and natural resource issues. In the early 1980s, the book by Herman Daly Steady-State Economics [13] (see also [14]) and his insights into the flow-stock problem were a fresh new impulse for conceptualizing the environmental costs in a revised national accounting system. Daly called our attention to the fact that economic growth is defined as a measure of 'flow' rather than 'stock'. In recent decades, measures of flow have increasingly been seen as measures of economic and political success. Prevailing attitudes in politics and business took no notice of the effects of the exponential growth of flows - such as GDP, private and public consumption, energy and raw material use, pollution and waste flows - on stocks like the assets of nature. They overlooked the fact that the flows themselves depended on the continuing maintenance of these stocks.

Daly is here in the tradition of Irving Fisher and Kenneth Boulding [15], who pointed out the problems inherent in the use of GDP as a goal measure for economic policy or as an indicator of social welfare. Fisher [16] pointed to the decisive reference concept for a measure of social welfare, which is capital stock, from which the 'psychic income' (the consumers' 'subjective enjoyment') is derived. Boulding was the first economist to place Fisher's central idea in an ecological context of finite environmental assets and resources. He defined the goal of maximum economic growth as a 
collective error of mainstream economics. From an ecological standpoint the goal should be the opposite: to achieve a socially defined level of economic welfare while minimizing the necessary levels of production and consumption.

Implementation efforts for installing facets of green accounting at the national and international level were more or less lacking throughout the emergence of 'environmentalism' in the 1980s to the 1990s [17]. This can perhaps be attributed to the lack of commitment on the part of international institutions, as observed by the Club of Rome and the WWF. There was firstly an unwillingness to provide financial and technical support for the 'greening' of the system of national accounts at national, regional and international levels, and, secondly, the absence of a leading international institution with the technical expertise, financial resources, and political leverage to promote the necessary reform.

FMP: Your work on defensive expenditures is still cited in economic literature and practice. They are actually a bridge between the traditional economic accounting and some unresolved environmental problems. What was your former approach and how useful is the concept of defensive expenditures today?

CL: The traditional indicator of economic growth transforms a failure into a success. GDP increases in the wake of a production process that disregards the environment, and rises still further when the given environmental damages are mitigated by economic activities. The expenditures associated with these counter-actions are generally called compensatory or defensive expenditures.

The national accounting concepts of GDP and economic growth (increase in GDP) are undiscriminating. All apparently final monetary economic activities are added to GDP regardless of their purpose and the function they play in production and consumption. The aggregation of economic activities into GDP is doubtlessly useful as an aid to stabilization and fiscal policy, which requires information about the level and change of market production, income distribution, and consumer and investment expenditures - irrespective of their contribution to quality of life. However, the one-dimensional concept of GDP is clearly inadequate when the aim is to calculate a measure of true net income, net of all costs of keeping capital (including natural capital) intact. To an (ever) increasing extent, GDP contains transactions that cannot be given as such a positive value, and whose sole function is to repair damage and avoid environmental burdens brought about by the negative effects of economic activities: defensive expenditures.

Defensive expenditures comprise those economic activities by which we defend ourselves against the unwanted side effects (negative external effects) of our aggregate production and consumption. They are understood as expenditures to cure, neutralize, eliminate, avoid, and anticipate burdens on and damage to the environment (and living conditions in general) caused by the economic process in industrial countries. They are not superfluous in the short term. Under current economic, technological, and environmental conditions, they are both necessary and useful. Expenditures on environmental preservation and restoration fulfill positive functions here and now. First, their causal relationship allows the cost nature of these expenditures to become clear: the deterioration of certain environmental and living conditions is historically linked to the process of economic growth, the market outputs of which are recorded unaltered in the GDP. However, the expenditures that compensate for these problems or attempt, in view of the serious risks, to prevent them are additional expenses made to achieve the conventional bundle goods-and-services plus environmental services which were formerly cost-free or nearly cost-free.

Environmentally defensive expenditures arise with the transition of the environment as a free good to the environment as a scarce good. With the growing environmental burden and natural resource needs of the growth process in the industrial world, it became increasingly costly to obtain the normal productive and consumptive services of the environment we were accustomed to having (nearly) cost-free in the past. At the beginning of the new 'era' of scarce environmental services, 
the 1970s, we had to pay mainly for purifying polluted air and water and for reducing (the negative effects of) noise emissions. In the 1980s we were forced to pay additionally for cleaning up polluted soils; for purifying contaminated groundwater; for meeting stricter emission standards for air pollutants, wastewater, and waste disposal; for repairing damages to buildings and works of art; and for treating damaged forests.

Since the end of the 1980s, we have reached another higher rung on the ladder of costs and are even now also paying for substituting ozone-depleting CFCs, for mitigating the greenhouse effect, for securing biodiversity in terrestrial and maritime ecosystems, and for developing new, more environmentally friendly systems of transport and energy, chemical and agricultural production.

Seen from a dynamic perspective, defensive expenditures are additional economic costs incurred by a specific pattern of growth and development. Parts of the final production indicated in the net domestic product (NDP) are not outputs but inputs, i.e. production and consumption costs. The environmentally defensive expenditures can be interpreted as a real income transfer from the human production system to the environment. They are comparable with the real income transfer from the oil-consuming countries to the OPEC states after the oil price explosions in 1973/74, 1979/80 and since 2004. These real income transfers amount to a loss of income that cannot be spent once again for production or investment.

The concept of defensive expenditures demonstrates that in certain cases less can be more, and vice versa. The development of certain environmentally detrimental, materials- and energy-wasting, and geographically centralized economic structures necessitates additional compensatory expenditures to achieve unaltered economic, social, and environmental goals. A change in these types of costraising economic and technological structures could lead to a reduction of (defensive) expenditures without a reduction in the quality of life.

The concept of defensive expenditures is still important. No other concept can better illustrate the illusory character of economic growth as a welfare increase in a time of environmental disruption, urban sprawl, and intensive energy and natural resource consumption. I always had the intention to make a project concentrating on the conceptual clarification and the empirical dimensions of defensive expenditures in an industrial country. In the 1980s, with a colleague from the International Institute of Environment of the Science Center Berlin, I made a project aiming at the calculation of the magnitude and growth of defensive expenditures for West Germany between 1970 and 1988 [18-20]. This project was performed in a small research group at the Science Center Berlin with the support of the Volkswagen Foundation for a period of three and a half years.

According to our calculations, we observed an absolute and relative increase in both main categories of environmental defensive expenditures: (a) environmental protection costs to avoid a decline in environmental quality and (b) repair, treatment, and cleaning-up expenditures, resulting from (nonavoided) environmental burdens and damages. The total burden of society with environmental defensive costs increased in the (former) Federal Republic of Germany, in relation to GDP, from $1.5 \%$ in 1970 to $3.4 \%$ in 1988 . While the total GDP increased in this nearly 20 years time period by $50 \%$, total environmental defensive expenditures leaped by more than $300 \%$. (These figures do not represent genuine percentages of GDP, but rather a ratio, since certain cases of double accounting could not be avoided.) At the end of the 1980s, nearly one twenty-fifth of the production included in GDP was consumed to prevent, dispose of, repair, and compensate for the environmental destruction caused by the environmental impact of economic growth.

Environmental defensive expenditures are basically the economic expression of ecologically unsound development in the industrial world. They are a belated indicator of that maldevelopment because a society does not usually react with costly protective measures until the countervailing measures can no longer be postponed. In that sense they are only a part of the whole. In many 
spheres they indicate only the tip of the iceberg. We need to account for the net environmental damage and for the net deductions of natural assets that we observe. Consequently, the total economic costs of attaining a certain standard of sustainability ('keep capital intact') are the actual 'maintenance' investments (actual defensive costs) plus a monetary estimate of the net degradation and depletion of natural assets.

In the wider concept of defensive expenditures used in the project, we distinguished on the whole six spheres in which major ecological and social costs occur: the environment, transport, housing, security, health, and work. These spheres are not mutually exclusive. On the contrary, they overlap through their systemic linkages, which exist between the environment and health, for example, and between the environment and transport.

A key mechanism generating ecological and social costs is the process of spatial concentration (urbanization and agglomeration) in the course of the economic growth process. The market logic of this process is rooted in the economic advantages that agglomerated areas offer firms (the so-called agglomeration economies). Environmental problems necessarily began in agglomerated areas, and they are still centers of environmental degradation, although more and more attention has been shifted to long-range processes of pollution and contamination (such as the increasing concentration of carbon dioxide in the atmosphere and the pollution of oceans and seas).

Some categories of defensive expenditure are the following:

1. Defensive expenditures as a reaction to the environmental externalities of economic growth:

- investments in, and running costs of environmental protection in industry and the public sector;

- expenditures, caused by non-prevented pollutants, for repairs, for example, of domestic and commercial buildings, production facilities, motorways and railway bridges, high-voltage pylons, historic monuments, and works of art, as well as costs arising from damages to human health, to crops, and from needed cleaning of exposed surfaces and objects.

2. Defensive expenditures associated with spatial concentration, centralization of production, and urbanization: rising costs of getting to work (car use, commuting, etc.), increasing expenditures on rents, housing, and land use, on public and private security.

3. Defensive expenditures due to increased risks associated with mature industrial systems: for protection against increasing crime and higher vulnerability to criminal acts, and growing insecurity in urban areas.

4. Defensive expenditures arising from the damage costs of car transport: by the need to provide for medical treatment and rehabilitation of injured persons, for repair or replacement of damaged vehicles, and to cover costs of emission-reducing measures and equipment.

5. Defensive expenditures arising from unhealthy consumption and behavioral patterns and from poor working and living conditions: costs generated by smoking, poor nutrition, excessive alcohol consumption, drug use, industrial diseases and accidents, and the psycho-social health effects of protracted unemployment.

According to my calculations (entailed in depth in [18], pp. 131-309), the proportion of all defensive costs in the five categories increased - in relation to the GDP - in the time period 1970-88 from $6.8 \%$ to $11.6 \%$ (p. 133). In absolute figures the GDP grew by nearly $50 \%$, whereas the burden of the total defensive costs to society increased by nearly $150 \%$ - three times as much as the growth of the GDP. In this 18 -year period, $21 \%$ of the entire economic growth consists of the increase in defensive costs. If one subtracts the increase of the defensive expenditures from the growth of GDP in that period, the genuine growth rate drops to nearly $40 \%$ instead of $50 \%$. 
The problems which are described by the existence and dynamics of defensive expenditures are still pervasive today. There is still the tendency in society and politics to react late, after the environmental and resource problems have occurred. So, the industrial world is still evolving according to the pattern of growth and spatial concentration, which is environmentally disrupting and resourceand energy-wasting. The modest achievements regarding low increases of the energy and resource productivity in some industrial countries cannot change this assessment.

One example: A new projection of the German Institute of Economic Research (DIW) estimates the costs of the climate change for Germany until 2050 roughly at 800 billion euro (Der Tagesspiegel, 15 March 2007, p. 2). Only 170 billion euros are required for adjusting the country (the towns, the coasts, etc.) to the new, warmer climate. These adjustment costs are typical defensive costs, compensating negative effects of climate change. About 300 billion euro is the amount of costs which have to be paid for higher energy prices. And 330 billion euros are estimated for the costs of damages, caused by the climate change that was not prevented by avoidance activities.

Defensive expenditures are a cornerstone in the calculation of the index of sustainable economic welfare (ISEW), which was developed by Daly and Cobb in 1989 [21] and which created a new line of research. This index, like similar indices, has been calculated for several national economies such as USA, Germany, Italy, UK, Sweden, Chile, and Poland. The research group at the University of Siena has been developing regional measures of ISEW for several years [22-24]. It would be worthwhile to supplement the research on ISEW and similar indices (which use a wider concept of ecological and social costs of the economic growth process - including monetary estimates of environmental damage and net depletion of (non-renewable) natural resources) with a new calculation of the size and dynamics of defensive expenditures in this era of the struggle against climate change, which we evolve in.

FMP: What were the expectations from your work?

CL: I expected to contribute to raise the awareness among economists about the other side of the economic growth coin: the (growth accompanying) increasing social costs of environmental losses and damages as well as other impairments of the living conditions. At the time when I wrote my $\mathrm{PhD}$, I could not demonstrate empirically that the magnitude of defensive expenditures was increasing steadily and that it grew much faster than the GDP. As we saw, this was a major result of the empirical project at the Science Center Berlin in the second half of the 1980s.

In the mid-1970s, many researchers in this field expected that a system of social indicators should serve as the central measure of social and individual welfare in economics and economic policy, instead of a one-dimensional revised welfare-orientated GDP. We underestimated in these years of hope and reform spirit for a better policy, focused on the objective of improvements of quality of life for all, the fixation of the economic profession on the macro-aggregates of national accounts. Despite all criticism of GDP used as a welfare measure, most economists used further the GDP resp. its growth rate as a goal indicator and did not take into consideration so much the system of social indicators which had been developed in a big coordinated effort by the OECD in a nearly 10 -year period. That is why the proponents for substituting the inadequate GDP used as a welfare measure by a 'green' net product or net consumption figure, like ISEW, always start by adding and/or deducting additional production/consumption costs or benefits to a national accounts aggregate.

FMP: Which of these ideas are still topical and can be used to increase our awareness of certain problems?

CL: Various ideas are still topical. 
- The flow-stock problem. The stock concept of the system of national accounts needs to be broadened to include especially the stock of environmental assets (assimilation potentials, etc.) and (non)renewable natural resources. Until today, the obsolete economic growth concept is reigning, which counts the consumption of natural resources and the degradation of the environment positively as income. The prevailing concept of growth creates a big growth and welfare illusion which is exactly why most governments and also major forces in business and economic science are resisting against a disillusioning, but timely ecological adjustment of the growth concept.

- Still topical is the problem of environmental costs of economic growth (including the costs of fighting climate change). The concept of defensive expenditures, which entails part of the environmental costs, is still helpful and important in showing the (potential) counter-productiveness of an undifferentiated economic growth strategy. Politically speaking, the policy of pursuing the highest possible economic growth is discredited by the exposure of defensive expenditures. Under the present conditions of economic development, in which productive as well as destructive forces are at work, it can no longer be taken for granted that economic growth goes hand in hand with an increase of welfare. What is needed is a policy of differentiated development that addresses the structural causes of environmentally damaging and costly patterns of production and consumption, which eliminates or at least curbs the sources of perpetual new damages and steadily increasing defensive costs.

- The idea that a big and potentially increasing part of economic welfare is produced in the private household sphere, which is not recorded in the market-price-orientated concept of GDP.

- A policy of undifferentiated economic growth should be outdated, but it is, as we know, not. Economic growth seems to be more than ever the solution of nearly all political and social problems, primarily for combatting and decreasing unemployment. Even the Greens, prolific growth critics in the 1980s, seem to have lost their growth-critical spirit. A concept of an environmentally benign and energy and resource saving production and consumption pattern is very timely. A policy of undifferentiated economic growth according to the adage 'Economic growth is not all, but without growth all is nothing' and the present imperatives for preventing the climate catastrophe do not fit together any more at all.

FMP: Some national governments are meeting the need to include the value of natural capital into the measure of national wealth. The first contributions in the field of environmental accounting were in the 1970s and 1980s and the debate is still open [25]. However, a national accounting system widely acknowledged is far from being standardized. How is it possible to foresee some changes to the traditional economic framework that is so consolidated?

CL: If the issues are overwhelming and long lasting, criticism and reform will not exhaust, although national accounts and its institutional settings seem so consolidated. Not to forget, that the measurement problems of various facets of non-market items and social costs seem often insurmountable. Research on alternatives to the outdated welfare concept of undifferentiated GDP growth was easier with the rail wind of the reform era in the 1970s and was furthered in the 1980s by the rising consciousness regarding the increasing negative environmental effects of economic growth and the rise of the Green Party in Germany and other west European countries. The Greens in the (west) German parliament supported research on the incremental social and environmental costs of economic growth and on the rising defensive expenditures. They organized press conferences to divulge this growth-critical information and also hearings in the parliament on the deficiencies of the system of national accounts in an environmental context. They promoted alternative ways of measuring welfare that could guide a new policy of qualitative, environmentally friendly economic growth. 
Since the mid-1990s, economic problems like mass unemployment, widening disparities in the income distribution, and growing poverty problems dominated the political agenda in western societies again. They increased the sense of economic insecurity and existential anxiety in increasing parts of the population. Accordingly, the interest for environmental issues and for qualitative questions like the qualitative content of the growth pattern seemed to diminish. Actually, environmental issues are back on the top of the political agenda. The new report of the UN on climate change has made the climate issue the number one political theme worldwide.

FMP: In his book Beyond Growth, Herman Daly describes the multiform context in which the idea of defensive expenditures must be set. 'The explosion of the populations of human bodies, of artifacts of all kinds, and of the populations of plants and animals exploited for human use that has happened in the past fifty years might better be called an implosion, since it has occurred in a finite environment. The term implosion suggests a compressing together rather than an expanding apart, a process of congestion, mutual interference, and self-canceling collision. Defensive expenditures reflect this increasingly prevalent phenomenon of mutually interfering, self-canceling activities' ([26], p. 101). And he cited you as the promoter of this concept. What about ecological economics and do you think it can contribute to widen the economic horizon, also in the light of the present environmental problems?

CL: Environmental problems were in economics first perceived as micro-problems, but the precarious coevolution of economic and ecological systems in the last decades has changed these microproblems almost overnight into macro-problems, which the analytical instruments of environmental economics are not prepared for. The new experience is that the system as a whole, the global ecosystem, is threatened and not only in its different parts. For example, the assimilation capacities of the (global) ecosystem are limited, they are absolutely, not only relatively scarce. Because ecological knowledge becomes decisive for the determination of the maximum physical expansion of the economic system, we can speak of the necessary ecologizing of economics that complements the economizing of ecology in the micro-context which is the central theme of neoclassical environmental economics.

The resource sources and the waste sinks of the earth like air, water, and the soil are part of the finite terrestrial system and consequently also finite. The adequate political concept is no longer unlimited economic growth, but sustainable development, a mode of economic and social development that can be sustained ecologically forever. The ultimate objective of economic activities is not maximum production of material goods and services, but to provide what is necessary for the requirements for 'enjoyment of life', as Georgescu-Roegen puts it, for 'quality of life' or 'individual well-being'. Economics has neglected for a long time the difference between wants and needs. Needs are finite contrary to wants which emerge continually in new forms and are therefore insatiable.

FMP: The concept of transdisciplinarity is becoming fundamental when facing complex questions such as environmental ones. It implies the integration of disciplines and instruments in order to create something new. Do you think economics is ready to deal with such a necessary integration? And what do you think about the future evolution of economic theory under a sustainability point of view?

CL: The one-sided orientation of modern societies on economic progress (on maximum growth of the GDP) has caused an ecological crisis that threatens the human economies. The negative impacts of an economic system almost totally released from its cultural surrounding - regarding ecological, social, and moral values - could be interpreted as an argument for re-embedding the economic system in the ecological, social, moral, and political framework of society. 
The tasks of ecological economics can only be formulated and adequately elaborated if economic theory is open to ecology and other natural sciences. Economics should also widen its perspective according to philosophy, ethics, cultural anthropology, and ethnology to be better equipped for trans- and interdisciplinary analyses of potential development modes and lifestyles which simultaneously are meeting basic needs criteria as well as the criteria for ecological sustainability.

An economic science with ecological foundations needs above all to be oriented on an unlimited time-continuum. The living generations are members in a chain of generations. Economics should address the political-ethical question of balancing the legitimacy of the demands - regarding the consumption/depletion of natural resources - of present and future generations. This can only be done satisfactorily in close cooperation with philosophical ethics and in a dialog with the big religions.

Among economists, it is not yet possible to perceive any move away from the path of a pure economic, mathematically formulated neoclassical theory of general equilibrium. The neoliberal turn in economics which began in the course of the 1970s continues, although the economic policy results following the recommendations of the supply oriented neoliberals are disappointing and partially disastrous. The detrimental effects of globalization on increasing parts of the population of Western Europe and the challenge of the threatening climate catastrophe and other dangerous environmental and resource crises call for a re-embedding of economics as mentioned before. This implies a primacy of politics in determining a political, social, and ecological framework for the market economy. Today this primacy is still in danger.

The business sector, specifically the big transnational enterprises in the new era of globalization, has become the dominating factor in political decision-making in the Western hemisphere. A re-embedding implies that the political sphere acquires back this primacy. The climate issue which will dominate, in all likelihood, the political agenda worldwide in the coming decades cannot be solved satisfactorily by economic theory except by internalizing the basic principles of ecological economics and sustainability theory into the corpus of economics.

\section{REFERENCES}

[1] Gross, B.M., The state of the nation: social system accounting. Social Indicators, ed. R.A. Bauer, MIT Press: Cambridge, MA, and London, 1966.

[2] Leipert, C., Unzulänglichkeiten des Sozialprodukts in seiner Eigenschaft als Wohlstandsmaß (Inadequacies of the national product as a measure of welfare), J.C.B. Mohr (Paul Siebeck): Tübingen, 1975.

[3] Leipert, C., A critical appraisal of gross national product: the measurement of net national welfare and environmental accounting. Journal of Economic Issues, 21(1), pp. 357-373, 1987.

[4] Kuznets, S., Government product and national income. Income and Wealth (Series 1), ed. E. Lundberg, International Association for Research in Income and Wealth: Cambridge, 1951.

[5] Kuznets, S., Concluding remarks. The Measurement of Economic and Social Performance, Studies in Income and Wealth, Vol. 38, ed. M. Moss, Columbia University Press: New York, 1973.

[6] Kuznets, S., National income and industrial structure. Economic Change: Selected Essays in Business Cycles, National Income and Economic Growth, Heinemann: London, 1954.

[7] Sametz, A.W., Production of goods and services. Indicators of Social Change: Concepts and Measurements, eds E.B. Sheldon \& W.E. Moore, Russell Sage Foundation: New York, 1968.

[8] Nordhaus, W. \& Tobin, J., Is growth obsolete? National Bureau of Economic Research, General Series 96, New York, 1972. 
[9] Economic Council of Japan, Measuring Net National Welfare of Japan, ECJ: Tokyo, 1973.

[10] Zolotas, X., Economic Growth and Declining Social Welfare, Bank of Greece: Athens, 1981.

[11] Kuznets, S., National Income. A Summary of Findings, National Bureau of Economic Research: New York, 1946.

[12] Daly, H.E., Research proposal to the World Bank on development anomalies and National Accounts, mimeo, Louisiana State University, Baton Rouge, 1983.

[13] Daly, H.E., Steady-State Economics, Freeman Publ.: San Francisco, 1977.

[14] Daly, H.E. (ed.), The steady-state economy: alternative to growthmania. The Other Economic Summit, Conference Papers of the Other Economic Summit, London, 1984.

[15] Boulding, K.E., Income or welfare. Review of Economic Studies, 17, pp. 77-86, 1949/1950.

[16] Fisher, I., The Nature of Capital and Income, The MacMillan Co.: New York, 1906.

[17] Brouwer, R. \& Leipert, C., The role of environmental protection expenditures in integrated economic-environmental accounting: tuning theoretical perspectives and statistical realities. International Journal of Sustainable Development, 2(1), pp. 185-200, 1999.

[18] Leipert, C., Die heimlichen Kosten des Fortschritts. Wie Umweltzerstörung das Wirtschaftswachstum fördert (The Hidden Costs of Progress. How Environmental Disruption Furthers Economic Growth), S. Fischer Verlag: Frankfurt/Main, 1989.

[19] Leipert, C., Social costs of the economic process and national accounts: the example of defensive expenditures. Journal of Interdisciplinary Economics, 3(1), pp. 27-46, 1989.

[20] Leipert, C., Defensive expenditures. Taking Nature into Account. Toward a Sustainable National Income. A Report to the Club of Rome, ed. W. van Dieren, Copernicus-Springer Publishers: New York, pp. 175-186, 1995.

[21] Daly, H.E. \& Cobb, J.B., Jr., For the Common Good, Beacon Press: Boston, 1989.

[22] Pulselli, F.M., Ciampalini, F., Tiezzi, E. \& Zappia, C., The index of sustainable economic welfare (ISEW) for a local authority: a case study in Italy. Ecological Economics, 60(1), pp. 271-281, 2006.

[23] Pulselli, F.M., Bastianoni, S., Marchettini, N. \& Tiezzi, E., La soglia della sostenibilità, ovvero quello che il PIL non dice, Donzelli: Rome, 2007.

[24] Pulselli, F.M., Bastianoni, S., Marchettini, N. \& Tiezzi, E., The Road to Sustainability - GDP and the Future Generations, WIT Press: Southampton (forthcoming).

[25] Lange, G.M. (ed.), Special issue on Environmental Accounting: Introducing the System of Integrated Environmental and Economic Accounting 2003 - SEEA-2003. Ecological Economics, 61(4), pp. 589-724, 2007.

[26] Daly, H.E., Beyond Growth - The Economics of Sustainable Development, Beacon Press: Boston, 1996. 